\title{
PENGARUH MODEL PEMBELAJARAN GENERATIF TERHADAP HASIL BELAJAR MENGINDENTIFIKASI ILMU BANGUNAN GEDUNG SISWA KELAS X TEKNIK KONSTRUKSI BANGUNAN SMK NEGERI 2 MEDAN
}

\author{
Dely Kurnia Putri ${ }^{1}$, Putri Lyanna A.Luthan ${ }^{2}$ \\ ${ }^{1}$ Alumni Program Studi Pendidikan Teknik Bangunan, Fakultas Teknik UNIMED \\ ${ }^{2}$ Dosen Pengajar Jurusan Pendidikan Teknik Bangunan, Fakultas Teknik UNIMED \\ (Putri.lynna@gmail.com)
}

\begin{abstract}
ABSTRAK
Penelitian ini bertujuan untuk mengetahui pengaruh penggunaan dan hasil belajar siswa model Pembelajaran Generatif yang memberi pengaruh yang berbeda terhadap hasil belajar pada mata pelajaran Mengidentifikasi ilmu bangunan gedung pada siswa kelas $X$ semester genap program keahlian konstruksi bangunan SMK Negeri 2 Medan Tahun Ajaran 2014/2015 dibandingkan menggunakan pembelajaran konvensional.

Populasi ini adalah semua siswa X Program Keahlihan Teknik Konstruksi Bangunan SMK Negeri 2 Medan tahun pelajaran 2014/2015 yang terdiri dari 2 kelas sebanyak 70 orang. Sampel dalam penelitian ini adalah siswa kelas X Program Keahlian Konstruksi Bangunan SMK Negeri 2 Medan yang terdiri dari dua kelas, kelas X TKB-A berjumlah 35 orang dan kelas X TKB-B berjumlah 35 orang siswa. Sehingga jumlah keseluruhan siswa terdiri dari 70 siswa. Instrumen yang digunakan untuk mengumpulkan data adalah post tes dan pre tes dalam bentuk soal pilihan berganda. Metode dan rancangan penelitian eksperimen menggunakan desain ANAVA $1 \times 1$. Variabel penelitian memenuhi persyaratan normalitas dikaji dengan uji Liliefors dan memenuhi persyaratan homogenitas dengan uji F.

Berdasarkan hasil penelitian ini, hasil belajar siswa yang diajar dengan model pembelajaran Generatif lebih tinggi jika dibandingkan dengan hasil belajar siswa yang diajar dengan menggunakan Model Konvensional, yaitu diperoleh nilai $t_{\text {hitung }}=3,379$ dan $t_{\text {tabel }}=1,671$, sehingga $t_{\text {hitung }}>t_{\text {tabel }}$, dengan taraf signifikan $a=0,05$. Dengan demikian dapat disimpulkan bahwa penggunaan model Pembelajaran Generative memberi pengaruh yang berbeda terhadap hasil belajar Mengidentifikasi Ilmu Bangunan Gedung Gedung pada siswa kelas X Program Keahlian Konstruksi Bangunan di SMK Negeri 2 Medan Tahun Pelajaran 2014/2015.
\end{abstract}

Kata Kunci : Model Pembelajaran Generatif, Hasil Belajar, Ilmu Bangunan Gedung

\begin{abstract}
.
This study aims to determine the influence of usage and student learning outcomes Generative Learning model which gives a different effect on learning outcomes in subjects Identify the science building in class X semester building construction skills program SMK Negeri 2 Medan Academic Year 2014/2015 compared using conventional learning.

These populations are all skills to students X Program Building Construction Engineering SMK Negeri 2 Medan 2014/2015 school year consisting of two classes of 70 people. The sample in this study were students of class X Building Construction Skills Program SMK Negeri 2 Medan, which consists of two classes, Class X TKB-A numbered 35 and TKB-B X class numbered 35 students. So that the total number of students consisted of 70 students. The instrument used to collect data is post-test and pre-test in the form of multiple choice questions. Methods and experimental research design using ANOVA design $1 \times 1$. Variables meet the requirements assessed by test Liliefors normality and homogeneity test meets the requirements of $F$.
\end{abstract}


Based on these results, the learning outcomes of students who are taught by learning model Generative higher when compared to the learning outcomes of students who are taught by using Model Conventional, the obtained value $t=3.379$ and table $=1.671$, so thitung $>$ ttable, with significance level $a=0.05$. It can be concluded that the use of Generative Learning model gives a different effect on learning outcomes Identify Building Sciences Building in class X Building Construction Skills Program at SMK Negeri 2 Medan academic year 2014/2015.

Keywords: Generative Learning Model, Learning Outcomes, Science Building

\section{Pendahuluan}

Pendidikan yang mampu mendukung pembangunan di masa mendatang adalah pendidikan yang mampu mengembangkan potensi siswa, sehingga yang bersangkutan mampu menghadapi dan memecahkan problema kehidupan yang dihadapinya. Dalam upaya peningkatan mutu pendidikan banyak hal yang harus diperhatikan, antara lain : hasil belajar, proses belajar mengajar, model pembelajaran yang sesuai dengan materi ajar, fasilitas belajar dan profesionalisme guru. Proses belajar mengajar merupakan unsur yang paling penting yang harus diperhatikan karena dengan pelaksanaan proses belajar mengajar yang baik tersebut tujuan pendidikan akan tercapai.

SMK Negeri 2 Medan merupakan lembaga pendidikan formal yang memiliki jurusan Teknik Bangunan, dalam melaksanakan serangkaian kegiatan belajar yang meliputi1. berbagai mata pelajaran keteknikan.

Berdasarkan hasil observasi sekolah yang diperoleh dari guru mata pelajaran Mengidentifikasi Ilmu Bangunan Gedung kelas $X$ bangunan program keahlihan Teknik Konstruksi Bangunan T.P.2013/2014 pada semester genap dapat dilihat persentase nilai yang diperoleh siswa . Dengan jumlah siswa 22 orang, yang memperoleh nilai $\leq 75$ kategori tidak kompeten sebanyak 31,81 \% (7 orang), nilai 75 - 84 kategori cukup kompeten 36,36\% (8 orang), nilai 85 - 94 kategori kompeten sebanyak 22,72 \% (5 orang), nilai $95-100$ kategori sangat kompeten sebanyak 9,09\% (2 orang).

Selama ini model pembelajaran yang diterapkan di SMK Negeri 2 Medan masih mengarah pada pembelajaran konvensional. Pada pembelajaran konvensional ini kebanyakan siswa hanya diam dan tidak memperhatikan apa yang disampaikan oleh guru, bahkan jika guru bertanya pada siswa sebagian besar siswa tidak mampu menjawab, dan terkadang satu orang siswa pun tidak mampu menjawab.

Diantara model pembelajaran yang dapat di gunakan yaitu model pembelajaran Inovatif Kontemporer yaitu Pembelajaran Generatif, yang diharapkan dapat meningkatkan hasil belajar siswa secara optimal dan memberikan kompetensi kognitif. Hal ini beranjak dari model pembelajaran Generatif yang menekankan pada pengintegrasian atau penekanan secara aktif pengetahuan baru dengan menggunakan pengetahuan awal siswa sebelumnya melalui 4 (empat) tahap pembelajaran yaitu tahap eksplorasi, pemfokusan, tantangan atau pengenalan konsep dan penerapan konsep. Dengan cara pengintegrasian tersebut pengetahuan siswa akan tersimpan dalam jangka waktu yang cukup lama di memori otak.

\section{Kajian Pustaka}

\subsection{Landasan Teoritis}

Hasil belajar yang dicapai seseorang dapat diketahui bila diadakan pengukuran dari pengetahuan seseorang itu. Untuk mengukur sampai dimana tingkat pengetahuan seseorang harus ada suatu alat pengukur tertentu yang fungsinya adalah mengukur pengetahuan hasil belajar, dan alat atau prosedur yang digunakan dinamakan tes. Hasil belajar biasanya dinyatakan dalam bentuk skor yang diperoleh siswa setelah mengikuti tes hasil belajar yang diadakan setelah selesainya suatu program pengajaran. Hal ini sejalan dengan yang diungkapkan oleh Sudjana (2009:28), bahwa prestasi belajar adalah penilaian dari usaha kegiatan yang dinyatakan dalam bentuk angka, huruf yang dapat mencerminkan hasil yang oleh seorang dalam jangka waktu tertentu. Setiap satu soal dapat dijawab oleh siswa maka diberi nilai satu dan sebaliknya jika menjawab salah maka diberi nilai nol. Selanjutnya untuk menghitung nilai yang diperoleh siswa dari soal-soal yang telah dijawab mereka adalah dengan pembagian dari jumlah soal yang 
berhasil dijawab benar dengan jumlah soal keseluruhannya dikali seratus. Pada akhirnya diharapkan penggunaan Model Pembelajaran Generatif tersebut dapat merubah keadaan belajar siswa pada Ilmu Bangunan, menjadi lebih baik dan mengacu kepada tingkat keberhasilan dalam belajar yang diorientasikan pada hasil belajar yang dicapai.

\subsection{Penelitian Yang Relevan}

Relevansi adalah sesuatu sifat yang terdapat pada penelitian yang dapat membantu penelitian dinilai relevan bila penelitian mempunyai topik yang sama, atau berhubungan dengan subjek yang diteliti. Dibawah ini disaikan beberapa hasil penelitian dimana model yang digunakan dengan penelitian ini, antara lain : Penelitian Nurul Syamsi (2014) dengan judul "Penerapan Model Pembelajaran Generatif Untuk Meningkatkan Hasil Belajar Fisika Siswa Pada Materi Elastisitas Di Kelas XI IPA SMA Laksamana Martadinata Medan T.P. 2011 / 2012" menyimpulkan bahwa ada pengaruh yang signifikan terhadap hasil belajar siswa pada materi elastisitas dikelas XI SMA Laksamana Martadinata dimana setelah pembelajaran selesai diberikan postes diperoleh dengan hasil rata - rata kelas eksperimen 72,1 dengan simpangan baku 12,1 sedangkan dikelas kontrol 69,5 dengan simpangan baku 15,4.

\subsection{Kerangka Konseptual}

Pada umumnya guru Mengidentifikasi Ilmu Bangunan Gedung masih menggunakan model pemebelajaran konvensional yang menitik beratkan pembelajaran pada metode ceramah. Dengan pembelajaran konvensional yang diterapkan oleh guru selama ini kurang melibatkan siswa artinya pembelajaran searah dimana guru memegang kendali sepenuhnya. Dengan demikian siswa menjadi kurang tertarik pada proses pembelajaran yang monoton sehingga mudah menimbulkan rasa jenuh. Pembelajaran konvensional lebih mengutamakan penyampaian informasi kepada siswa. Fokus guru adalah tercapainya seluruh perencanaan dalam scenario yang sudah disusun. Peneliti menawarkan Model Pembelajaran Generatif dimana dalam proses pembelajaran ini sangat penting kerjasama yang baik antara guru dan anak didik. Model Pembelajaran Generatif merupakan pembelajaran yang mengaktifkan siswa sehingga terjalin kerjasama yang baik antara guru dan siswa. Penelitian ini merupakan penelitian eksperimental yang menyelidiki pengaruh model pembelajaran Generatif, maka untuk keperluan ini diadakan perlakuan berupa penerapan model Pembelajaran Generatif terhadap kelompok eksperimen dan tanpa perlakuan pada kelompok kontrol.

\subsection{Hipotesis}

a. Hasil belajar siswa yang diajar dengan Model Pembelajaran Generatif pada mata pelajaran Mengidentifikasi Ilmu Bangunan Gedung memberi pengaruh yang berbeda jika dibandingkan dengan Konvensional pada siswa kelas X Program Keahlian Konstruksi Bangunan SMK Negeri 2 Medan T.P. 2014/2015.

b. Hasil belajar siswa yang diajar dengan Model Pembelajaran Generatif lebih tinggi pada mata pelajaran Mengidentifikasi Ilmu Bangunan Gedung jika dibandingkan dengan Konvensional pada siswa kelas $X$ Program Keahlian Konstruksi Bangunan SMK Negeri 2 Medan T.P. 2014/2015.

\section{Metode Penelitian}

Tempat penelitian ini dilaksanakan di SMK Negeri 2 Medan program keahlihan Konstruksi Bangunan pada mata pelajaran Mengidentifikasi Bangunan Gedung. penelitian ini dialaksanakan pada kelas X semester Genap, ddari tangal 19 juni 2014 sampai dengan 5 Maret 2015 Tahun Pelajaran (T.P) 2014/2015. Populasi dalam penelitian ini adalah semua siswa X Program Keahlihan Teknik Konstruksi Bangunan SMK Negeri 2 Medan tahun pelajaran 2014/2015 yang terdiri dari 2 kelas sebanyak 70 orang. Yang tiap - tiap kelasnya memiliki 35 siswa.

Pada penelitian ini yang digunakan adalah penelitian eksperimen semu (Quasi Eksperimen). Dalam penelitian ini terdapat 2 (dua) variabel yang menjadi titik perhatian untuk diteliti, yaitu:

a. Pada penelitian ini yang menjadi variabel terikat (Y) adalah hasil belajar Mengidentifikasi Ilmu Bangunan Gedung.

b. Variabel bebas $\left(\mathrm{Y}_{\mathrm{GL}}\right)$ pada penelitian ini adalah Model Pembelajaran Generatif.

c. Variabel bebas $\left(\mathrm{X}_{\mathrm{K}}\right)$ pada penelitian ini adalah model pembelajaran Konvensional.

\subsection{Desain Penelitian}

Penelitian ini melibatkan dua kelas yang diberikan perlakuan yang berbeda. Untuk 
mengetahui hasil belajar siswa dilakukan dengan memberikan tes pada kedua kelas sebelum dan sesudah diberikan perlakuan.

Rancangan penelitian dimaksud adalah seperti terlihat pada tabel berikut :

Tabel 1. Desain Penelitian Two group Pretest - Posttest Design

\begin{tabular}{cccc}
\hline Kelompok & $\begin{array}{c}\text { Pree - } \\
\text { Tes }\end{array}$ & Perlakuan & $\begin{array}{c}\text { Post - } \\
\text { Tes }\end{array}$ \\
\hline A-1 & $\mathrm{X}_{1}$ & $\mathrm{Y}_{\mathrm{GL}}$ & $\mathrm{X}_{2}$ \\
$\mathrm{~A}-2$ & $\mathrm{X}_{1}$ & $\mathrm{Y}_{\mathrm{K}}$ & $\mathrm{X}_{2}$ \\
\hline
\end{tabular}

\subsection{Teknik Pengumpulan Data}

Pada penelitian ini tes yang digunakan adalah tes pilihan berganda (Multiple Choice) yang terdiri dari empat option (pilihan). Jawaban yang benar diberi skor 1 (satu) dan jawaban yang salah diberi skor 0 (nol).

a. Uji Coba Instrumen

Uji coba instrument ini dilakukan pada siswa kelas XI - TKB 2 di SMK Negeri 2 Medan. Setelah dilakukan uji instrumen kepada 20 responden di SMK Negeri 2 Medan pada Kelas IX $\mathrm{TKB}_{2}$ maka dari 30 soal terdapat 25 soal yang valid dan 5 soal yang tidak valid.

b. Indeks kesukaran test

Soal yang baik adalah soal yang tidak terlalu mudah dan tidak terlalu sukar. Bilangan yang menunjukkan sukar dan mudahnya suatu soal disebut indeks kesukaran atau taraf kesukaran (Arikunto, 2007:176) sebagai berikut:

$$
P=\frac{B}{J S}
$$

Setelah dilakukan perhitungan kesukaran tes, dalam sebaran data uji coba indeks kesukaran tes pada mata pelajaran Mengidentifikasi Ilmu Bangunan Gedung terdapat 8 soal dalam kategori mudah, 17 soal dalam kategori sedang, dan 5 soal dalam kategori sulit.

\subsection{Uji Daya Pembeda Ttes}

Untuk menghitung daya pembeda tes hasil belajar Mengidentifikasi Ilmu Bangunan Gedung digunakan rumus Biddrich seperti dikemukakan oleh Arikunto (2007:177) sebagai berikut:

$$
D=\frac{B A}{J A}-\frac{B B}{J B}
$$

Berdasarkan sebaran data daya pembeda tes pada lampiran 8 , dan dari hasil perhitungan daya beda soal (lampiran 9) diperoleh 3 soal kategori sangat baik, 22 soal kategori baik, 2 soal kategori cukup, 3 soal kategori jelek.

\subsection{Reliabilitas Test}

Untuk menghitung reabilitas tes hasil belajar memahami bangunan gedung digunakan rumus Kuder dan Richardson, yaitu K-R20 yang diuraikan Arikunto (2007:100) sebagai Berikut

$$
r_{11}=\left(\frac{n}{n-1}\right)\left(\frac{s^{2}-\Sigma p \cdot q}{s^{2}}\right)
$$

Sesuai sebaran data uji coba reabilitas test pada lampiran 10, dan berdasarkan perhitungan indeks korelasi pada lampiran 11, indeks reliabilitas tes Mengidentifikasi Ilmu Bangunan Gedung termasuk dalam kategori sangat tinggi.

\section{Hasil Penelitian dan Pembahasan}

\subsection{Deskripsi Data Hasil Penelitian}

Pada kelas eksperimen berdasarkan data yang diperoleh dapat diketahui bahwa skor pretes pada kelas eksperimen diperoleh skor tertinggi $=22$ dan skor terendah $=8$, dengan rata-rata $=16,060$, Standart deviasi $(S D)=3,438$ dan varians $=11,820$. Dan skor pre-tes pada kelas kontrol diperoleh skor tertinggi $=22$ dan skor terendah $=8$, dengan rata-rata $=16,486$, standart deviasi $(\mathrm{SD})=3,165$ dan varians $=$ 10,022 .

Berdasarkan data dapat diketahui bahwa skor post-tes (tes akhir) pada kelas eksperimen diperoleh skor tertinggi $=24$ dan skor terendah $=13$, dengan rata-rata $=20,171$, standart deviasi $(\mathrm{SD})=2,985$ dan varians $=8,911$. Dan skor post-tes pada kelas kontrol diperoleh skor tertinggi $=23$ dan skor terendah $=12$, dengan rata-rata $=18,286$, standart deviasi $(\mathrm{SD})=2,875$ dan varians $=8,268$.

\subsection{Identifikasi Tingkat Kecenderungan Variabel Penelitian \\ Untuk mengidentifikasi tingkat} kecenderungan pada kelas eksperimen variabel penelitian dihitung dengan menggunakan nilai rata-rata ideal $(\mathrm{Mi})=14,5$ dan juga nilai standar deviasi ideal $(\mathrm{SDi})=4,16$. 
Tabel 2. Tingkat Kecendrungan Variabel Penelitian

\begin{tabular}{lccc}
\hline $\begin{array}{c}\text { Kelompok } \\
\text { Interval }\end{array}$ & F.Absolut & F.Relatif & Kategori \\
\hline $\begin{array}{l}20,74 \text { Sdi } \\
\text { s/d ke }\end{array}$ & 17 & $48,57 \%$ & Tinggi \\
atas & & & \\
$\begin{array}{l}14,5 \mathrm{~s} / \mathrm{d} \\
20,74\end{array}$ & 15 & $42,85 \%$ & Sedang \\
$8,26 \mathrm{~s} / \mathrm{d}$ & 3 & $8,57 \%$ & Kurang \\
$\begin{array}{l}14,5 \\
8,26 \mathrm{~s} / \mathrm{d}\end{array}$ & 0 & $0 \%$ & Rendah \\
ke bawah & & & \\
\hline \multicolumn{1}{c}{ Jumlah } & $\mathbf{3 5}$ & $\mathbf{1 0 0} \%$ & \\
\hline
\end{tabular}

Berdasarkan perhitungan di atas diperoleh bahwa siswa kelas $X$ Program Keahlian Konstruksi Bangunan di SMK Negeri 2 Medan Tahun Pelajaran 2014/2015 pada kelas eksperimen, mempunyai tingkat tes hasil belajar Mengidentifikasi Ilmu Bangunan Gedung cenderung tinggi.

Tabel 3. Data Tes Hasil Belajar Mengidentifikasi Ilmu Bangunan Gedung Cenderung Tinggi

\begin{tabular}{lccc}
\hline $\begin{array}{l}\text { Kelompok } \\
\text { Interval }\end{array}$ & F.Absolut & F.Relatif & Kategori \\
\hline $\begin{array}{l}20,74 \text { Sdi } \\
\text { s/d ke }\end{array}$ & 8 & $22,85 \%$ & Tinggi \\
atas & & & \\
$\begin{array}{l}14,5 \mathrm{~s} / \mathrm{d} \\
20,74\end{array}$ & 25 & $71,42 \%$ & Sedang \\
$8,26 \mathrm{~s} / \mathrm{d}$ & 2 & $5,71 \%$ & Kurang \\
$\begin{array}{l}14,5 \\
8,26 \mathrm{~s} / \mathrm{d}\end{array}$ & 0 & $0 \%$ & Rendah \\
ke bawah & & & \\
\hline Jumlah & $\mathbf{3 5}$ & $\mathbf{1 0 0 \%}$ & \\
\hline
\end{tabular}

Berdasarkan perhitungan di atas diperoleh bahwa siswa kelas $\mathrm{X}$ Program Keahlian Konstruksi Bangunan di SMK Negeri 2 Medan Tahun Ajaran 2014/2015 pada kelas kontrol, mempunyai tingkat tes hasil belajar Mengidentifikasi Ilmu Bangunan Gedung Gedung cenderung cukup.

\subsection{Uji Persyaratan Analis}

a. Uji normalitas

Pengujian normal tidaknya data dilakukan dengan menggunakan rumus uji lilliefors. Syarat normal dipenuhi apabila $\mathrm{L}_{\text {hitung }}<$ $\mathrm{L}_{\text {tabel }}$ pada taraf $\alpha=5 \%$.
Tabel 4. Uji Normalitas Menggunakan Rumus Uji Liliefors

\begin{tabular}{cccccc}
\hline $\begin{array}{c}\mathbf{N} \\
\mathbf{0}\end{array}$ & Data & Kelas & $\mathbf{L}_{\text {hitung }}$ & $\mathbf{L}_{\text {tabel }}$ & $\begin{array}{c}\text { Kesi } \\
\text { mpul } \\
\text { an }\end{array}$ \\
\hline 1 & Pre- & $\begin{array}{l}\text { Eksperi } \\
\text { men }\end{array}$ & 0,121 & 0,150 & Normal \\
& tes & $\begin{array}{l}\text { Kontrol } \\
2\end{array}$ & 0,078 & 0,150 & Normal \\
3 & Pos- & $\begin{array}{l}\text { Eksperi } \\
\text { men }\end{array}$ & 0,133 & 0,150 & Normal \\
4 & tes & $\begin{array}{l}\text { Kontrol } \\
4\end{array}$ & 0,064 & 0,150 & Normal \\
\hline
\end{tabular}

Dari table maka dapat disimpulkan bahwa data kedua kelompok sampel berdistribusi normal.

b. Uji Homogenitas

Analisis uji homogenitas yang menggunakan uji $\mathrm{F}$ yaitu membandingkan varians terbesar dan varians terkecil yaitu :

$$
F=\frac{\text { Varian terbesar }}{\text { Varian terkecil }}=\frac{S_{1}^{2}}{S_{2}^{2}} .
$$

Tabel 5. Uji Homogenitas

\begin{tabular}{cccccc} 
No & Data & Kelas & $\mathbf{F}_{\text {hitung }}$ & $\mathbf{F}_{\text {tabel }}$ & $\begin{array}{c}\text { Kesi } \\
\text { mpul } \\
\text { an }\end{array}$ \\
\hline 1 & $\begin{array}{c}\text { Pre- } \\
\text { tes }\end{array}$ & $\begin{array}{c}\text { Eksperimen } \\
\text { Kontrol }\end{array}$ & 1,397 & 1,82 & Hom \\
3 & $\begin{array}{c}\text { Pos- } \\
\text { Eksperimen } \\
\text { Kes }\end{array}$ & Kontrol & 1,0406 & $\begin{array}{c}1,82 \\
\text { ogen }\end{array}$ & Hom \\
ogen
\end{tabular}

Sehingga dapat dilihat bahwa $\mathrm{F}_{\text {hitung }}<$ $\mathrm{F}_{\text {tabel }}$ pada taraf nyata $\mathrm{a}=5 \%$ yang berarti data kedua sampel memiliki varians yang homogen dan berdasarkan dapat disimpulkan bahwa data penelitian telah memenuhi syarat untuk dilakukan pengujian hipotesis.

\subsection{Uji Hipotesis}

Dilakukan uji hipotesis untuk mengetahui apakah terdapat pengaruh yang berbeda antara hasil belajar siswa yang diajar dengan menggunakan model Pembelajaran generative dan hasil belajar siswa yang diajar dengan pembelajaran Konvensional dengan menggunakan rumus Analisis Varians (ANAVA) satu jalan. 
Tabel 6. Uji Hipotesis

\begin{tabular}{cccc}
\hline $\begin{array}{c}\text { Sumber } \\
\text { Data }\end{array}$ & $\mathbf{F}_{\mathbf{0}}$ & $\mathbf{F}_{\mathbf{t}} \mathbf{5 \%}$ & Kesimpulan \\
\hline Pre-tes & 0,379 & 3,988 & $\begin{array}{c}\mathrm{H}_{0}: \mu_{1}=\mu_{2} \\
\text { diterima }\end{array}$ \\
Post-tes & 5,7127 & 3,988 & $\begin{array}{c}\mathrm{H}_{0}: \mu_{1}=\mu_{2} \\
\text { ditolak }\end{array}$ \\
\hline
\end{tabular}

Dari hasil perhitungan uji hipotesis dengan rumus Analisis Varians satu jalan pada data pre-tes diperoleh bahwa $\mathrm{F}_{\text {hitung }}=0,379$ lebih kecil dari $\mathrm{F}_{\text {tabel }}=3,988$, maka hipotesis $\mathrm{H}_{0}$ : $\mu_{1}=\mu_{2}$ diterima dalam taraf nyata 0,05, sehingga dapat disimpulkan bahwa tidak ada perbedaan secara nyata untuk kedua model pembelajaran tersebut sebelum diberi perlakuan kepada kelas eksperimen dan kelas kontrol, dengan kata lain kemampuan awal siswa pada kelas eksperimen sama dengan kemampuan awal siswa pada kelas kontrol.

Sedangkan dari hasil perhitungan uji hipotesis dengan rumus Anava Varians satu jalan pada data post-tes diperoleh bahwa $F_{\text {hitung }}$ $=5,7127$ lebih besar dari $\mathrm{F}_{\text {tabel }}=3,988$, maka $\mathrm{H}_{0}$ : $\mu_{1}=\mu_{2}$ ditolak dan $\mathrm{H}_{1}: \mu_{1} \neq \mu_{2}$ diterima, dengan demikian hasil belajar Mengidentifikasi Ilmu Bangunan Gedung antara kelas eksperimen dan kelas kontrol jelas menunjukkan perbedaan, sehingga dapat dilanjutkan dengan uji-t. Dari perhitungan uji-t diperoleh $t_{\text {hitung }}=3,379$ dan $t_{\text {tabel }}=1,671$, karena $t_{\text {hitung }}>t_{\text {tabel }}$, maka $\mathrm{H}_{\mathrm{a}}$ diterima dan $\mathrm{H}_{0}$ ditolak, dan oleh karena itu dapat disimpulkan bahwa penggunaan model Pembelajaran Generative memberi pengaruh yang berbeda terhadap hasil belajar Mengidentifikasi Ilmu Bangunan Gedung Gedung pada siswa kelas X Program Keahlian Konstruksi Bangunan di SMK Negeri 2 Medan Tahun Pelajaran 2014/2015.

\subsection{Pembahasan Penelitian}

Pada awal penelitian ini diberikan tes awal kepada kelas eksperimen dan kelas kontrol, dan dari hasil tes awal yang dilakukan dapat disimpulkan bahwa tidak ada perbedaan secara nyata untuk kedua model pembelajaran tersebut sebelum diberi perlakuan kepada kelas eksperimen dan kelas kontrol, dengan kata lain kemampuan awal siswa pada kelas eksperimen sama dengan kemampuan awal siswa pada kelas kontrol.

Dari hasil uji hipotesis dengan rumus Analisis Varians (ANAVA) satu jalan, Mengidentifikasi Ilmu Bangunan Gedung Gedung antara kelas eksperimen dan kelas kontrol jelas menunjukkan perbedaan, sehingga dapat dilanjutkan dengan uji-t. Setelah dilakuakan perhitungan uji $t t_{\text {hitung }}>t_{\text {tabel }}$, maka $\mathrm{H}_{\mathrm{a}}$ diterima dan $\mathrm{H}_{0}$ ditolak, dan oleh karena itu dapat disimpulkan bahwa penggunaan model Pembelajaran generatif memberi pengaruh yang berbeda terhadap hasil belajar Mengidentifikasi Ilmu Bangunan Gedung pada siswa kelas X Program Keahlian Konsrtuksi Bangunan di SMK Negeri 2 Medan Tahun Pelajaran 2014/2015.

Hal ini disebabkan karena didalam penggunaan model Pembelajaran generatif memiliki kerangka pembelajaran yang Pada Model Pembelajaran Generatif terdiri atas 4 tahap yaitu : (a) pendahuluan atau tahap eksplorasi, (b) pemfokusan, (c) tantangan atau pengenalan konsep, dan (4) penerapan konsep. merupakan pembelajaran yang mendorong siswa untuk menghubungkan pengetahuan yang dimilikinya agar mendapatkan pengetahuan baru dan menerapkan pengetahuan tersebut pada permasalahan lain yang sejenis. Hal ini menuntut siswa untuk aktif menerima dan menghubungkan informasi yang masuk kemudian menempatkan informasi tersebut dalam memori panjang otaknya.

\section{Kesimpulan, Implikasi dan Saran}

\subsection{Kesimpulan}

Berdasarkan hasil penelitian yang telah diuraikan pada bab sebelumnya, maka dapat ditarik beberapa kesimpulan sebagai berikut:

a. Penggunaan model Pembelajaran Generatif memberi pengaruh yang berbeda terhadap hasil belajar Mengidentifikasi Ilmu Bangunan Gedung pada siswa kelas X Program Keahlian Teknik Konstruksi Bangunan SMK Negeri 2 Medan Tahun Pelajaran 2014/2015. Hal tersebut dapat dilihat dari hasil uji hipotesis diperoleh $t_{\text {hitung }}=3,379$ dan $t_{\text {tabel }}=1,671$, sehingga $t_{\text {hitung }}>t_{\text {tabel, }}$ maka $H_{a}$ pada siswa kelas $X$ Program Keahlian Konstruksi Bangunan SMK Negeri 2 Medan T.P. 2014/2015 diterima dan $\mathrm{H}_{0}$ Konvensional pada siswa kelas X Program Keahlian Konstruksi Bangunan SMK Negeri 2 Medan T.P. 2014/2015 ditolak.

b. Hasil belajar Mengidentifikasi Ilmu Bangunan Gedung pada siswa kelas $X$ Program Keahlian Teknik Konstruksi Bangunan SMK Negeri 2 Medan Tahun Pelajaran 2014/2015 yang diajar dengan menggunakan model Pembelajaran 
generatif lebih tinggi dibandingkan hasil belajar siswa yang diajar menggunakan pembelajaran Konvensional. Hal ini terlihat dari hasil belajar siswa yang menggunakan model Pembelajaran generatif memiliki rata-rata 26,171 sementara hasil belajar siswa yang menggunakan pembelajaran konvensional memiliki rata-rata 18,286.

\subsection{Implikasi}

Hasil kesimpulan menyatakan bahwa siswa yang diajar dengan menggunakan model Pembelajaran Generatif memperoleh hasil belajar Mengidentifikasi Ilmu Bangunan Gedung yang lebih tinggi jika dibandingkan dengan siswa yang diajar dengan menggunakan pembelajaran konvensional.

Secara aplikatif, guru mata pelajaran Mengidentifikasi Ilmu Bangunan Gedung harus senantiasa menyiapkan diri dalam mengantisipasi segala bentuk penyelesaian masalah belajar yang dialami siswa yang pada akhirnya memberikan respon terhadap hasil belajar yang diperoleh siswa.

\subsection{Saran}

Berdasarkan hasil penelitian, kesimpulan maka perlu disarankan beberapa hal sebagai berikut:

a. Kepala Sekolah hendaknya menyarankan kepada guru mata pelajaran Mengidentifikasi Ilmu Bangunan Gedung dengan pokok bahasan Menentukan Jenis Pondasi Yang Tepat Untuk Bangunan Sesuai Dengan Jenis Tanah agar menerapkan Model Pembelajaran Generatif yang telah diuji sebagai alternatif dalam meningkatkan hasil belajar siswa.

b. Dalam KBM guru mata pelajaran hendaknya mendorong siswa untuk menghubungkan pengetahuan yang dimilikinya agar mendapatkan pengetahuan baru dan menerapkan pengetahuan tersebut pada permasalahan lain yang sejenis.

c. Bagi peneliti dan guru mata pelajaran Mengidentifikasi Ilmu Bangunan Gedung agar lebih teliti dalam memanfaatkan pengalokasian waktu mengajar sesuai dengan tahap pembelajaran Generatif khususnya pada tahap pemfokusan dan tahap tantangan.

d. Bagi peneliti selanjutnya yang ingin meneliti tentang model pembelajaran generatif, disarankan mencari materi lain agar dapat membandingkan materi yang paling cocok untuk model pembelajaran generatif.

e. Bagi peneliti selanjutnya yang ingin meneliti tentang model pembelajaran generative lebih lanjut, diharapkan mampu mengelola kelas dengan baik sehingga pembelajaran yang efektif dapat tercapai.

\section{Daftar Pustaka}

Arends, R.I. 2007. Learning To Teach. New York: Mc Graw Hill.

Arikunto. 2002. Prosedur Penelitian Suatu Pendekatan Praktik. Jakarta: Pt Rineka Cipta.

Arikunto. 2010. Prosedur Penelitian (Edisi Revisi). Jakarta: Pt Rineka Cipta.

Djamarah, Syaiful. 2002. Strategi Belajar Mengajar (Rev.Ed).. Jakarta: Rineka Cipta.

Frick, Heinz. 1980. Ilmu Konstruksi Bangunan I . Yogyakarta: Kanisius.

Furchan, Arief. 1982. Pengantar Penelitian Dalam Pendidikan. Surabaya: Usaha Nasional

Gulo, W. 2000. Metodologi Penelitian. Jakarta: Grasindo.

Kardi, S Dan Nur, M. 2000. Pengajaran Langsung. Surabaya: University Press.

Kunandar.2008. Langkah Mudah Penelitian Tindakan Kelas Sebagai Pengembangan Profesi Guru. Jakarta: Rajawali Pers.

Lie, Anita.2009.cooperative learning mempraktikkan cooperative learningdiruang kelas. Jakarta: Grasindo

Sagala, Syaiful. 2009. Konsep Dan Makna Pembelajaran. Bandung: Alfabeta.

Sani, Ridwan,. 2013. Inovasi Pembelajaran. Jakarta: Bumi Aksara.

Sanjaya, W. 2007. Strategi Pembelajaran Berorientasi Standar Proses Pendidikan. Kencana Prenada Media Group: Jakarta.

Sardiman. 2009. Interaksi Dan Motivasi Belajar Mengajar. Jakarta: Pt. Raja Grasindo Persada.

Slameto. 2010. Belajar Dan Faktor - Faktor Yang Mempengaruhinya. Jakarta: Rineka Cipta.

Sudjana, Nana. 2002. Penilaian Hasil Proses Belajar Mengajar. Bandung: Sinar Baru.. 2005. Metoda Statika. Bandung: Sinar Baru..2009. Penilaian Hasil Proses Belajar Mengajar. Bandung: Sinar Baru. 
Sugiyono. 2009. Metode Penelitian Kuantitatif, Kualitatif \& Rnd. Bandung: Alfabeta.

Suprijono, Agus. 2010. Cooperative Learning Teori Dan Aplikasi Paikem. Yogyakarta: Pustaka Pelajar.

Suyatno. 2009. Menjelajah Pembelajaran Inovatif. Sidoarjo: Masmedia Buana Pustaka.

Wena. 2009. Strategi Pembeljaran Inovatif Kontemporer. Jakarta: Bumi Aksara.

Aisyah. 2014. Pengaruh Model Pembelajaran Generatif Terhadap Hasil Belajar Siswa Pada Materi Hukum Newton Di Kelas Semester I Smp Yayasan Perguruan Budi Agung Medan Marelan T.P. 2013 / 2014. Abstrak Skripsi Universitas Negeri Medan, Medan.

Nurul Syamsi. 2014. Penerapan Model Pembelajaran Generatif Untuk Meningkatkan Hasil Belajar Fisika Siswa Pada Materi Elastisitas Di Kelas Xi Ipa Sma Laksamana Martadinata Medan T.P. 2011 / 2012. Abstrak Skripsi Universitas Negeri Medan, Medan.

Sinaga Moriza. 2014. Pengaruh Model Pembelajaran Generatif Terhadap Hasil Belajar Siswa Pada Materi Pokok Hukum Newton Di Kelas X Semester I Sma Uisu T.P 2013/2014. Abstrak Skripsi Universitas Negeri Medan, Medan. 